\title{
Religiosidade, reprodução e saúde em famílias urbanas pobres
}

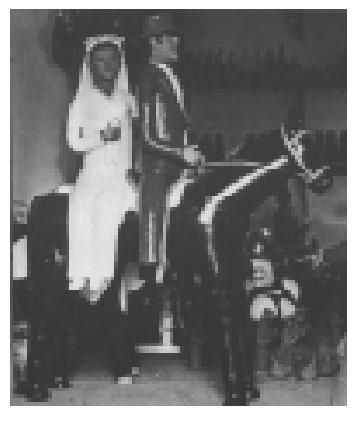

\author{
Márcia Thereza Couto ${ }^{1}$
}

COUTO, M. T. Religiosity, reproduction and health among underprivileged urban families. Interface _ Comunic, Saúde, Educ, v.5, n.8, p.27-44, 2001.

This article analyzes personal religious conversion within the context of family relations in the downscale suburbs of Recife, the capital of the state of Pernambuco, Brazil. It presents the results of a qualitative research study on the meanings of conversion for the members of the family and the ensuing transformations in their reproductive behavior. Based on the empirical data above, the article ends with a discussion of issues related to healthcare services in that area, and how the local inhabitants use them.

KEYWORDS: religion; urban population; family relations; reproduction; healthcare services.

Este trabalho analisa a conversão religiosa pessoal no contexto das relações familiares em uma área da periferia da cidade de Recife, Pernambuco-Brasil. Apresenta resultados de uma pesquisa de caráter qualitativo sobre os significados da conversão para os integrantes da família e as decorrentes transformações no comportamento reprodutivo. Por fim, com base neste material empírico, levanta algumas questões sobre os serviços de saúde existentes no bairro e o uso que a população faz destes.

PALAVRAS-CHAVE: religião; população urbana; relações familiares; reprodução; serviços de saúde.

\footnotetext{
${ }^{1}$ Doutoranda em Sociologia, Universidade Federal de Pernambuco. <marthe@cyberspace.com.br>
} 
O trabalho de pesquisa junto ao universo cotidiano de famílias urbanas pobres no Ibura, bairro da periferia de Recife-PE, e suas experiências de trânsito religioso entre inúmeras denominações pentecostais colocou-me por muitas vezes diante de "casos", sejam estes relacionados com conversões, escolhas religiosas ou mudanças de religião. Tomo como "casos" narrativas orais cuja matéria-prima são as vicissitudes do viver. Alguns acontecimentos extraordinários são reconhecidos pelos que contam como dignos de serem retidos na memória e atualizados, ou seja, contados.

Diferenciando-se de uma memória social no sentido estrito, "casos" são particulares à pessoa que conta ou a pessoas do círculo próximo; seus atores são, portanto, situados e nomeados. Para cientistas sociais "casos" como esses têm usualmente servido à reflexão sobre caminhos, buscas e encontros que, sendo particulares a cada indivíduo, dizem muito da serventia da religião nos dias de hoje numa sociedade cujo repertório do sagrado é quase inesgotável. Entretanto, neste artigo, quero explorar uma outra faceta deles, qual seja, a importância das adesões religiosas nas transformações instauradas na vida dos sujeitos e os significados que tais transformações trazem para as relações familiares. Com isto, pretendo trazer algumas contribuições para o diálogo estabelecido entre profissionais de saúde $e$ usuários, na medida em que discuto alguns dos efeitos da adesão religiosa nas representações e práticas de comportamento reprodutivo entre casais evangélicos.

Apresento um "caso", relatado por Maria José, uma mulher de 33 anos, criada numa família católica, casada, mãe de um garoto de quatro anos $e$ membro da Igreja Missão Evangélica Pentecostal há cinco anos. Maria José, ou Mazé como prefere ser chamada, acredita que aos 27 anos Deus mudou sua vida. Tendo conhecido seu atual marido cinco anos antes, lá mesmo no Ibura, Mazé se casa e logo pensa em ter um filho, seu grande sonho. Após um ano e meio engravida. Embora vivesse alguns conflitos com o marido por este ser "mulherengo", Mazé conta que sua gravidez estava indo bem.

Sempre cuidadosa, procurava não perder as consultas de pré-natal. Na consulta realizada aos seis meses, Mazé se desespera porque a médica diz

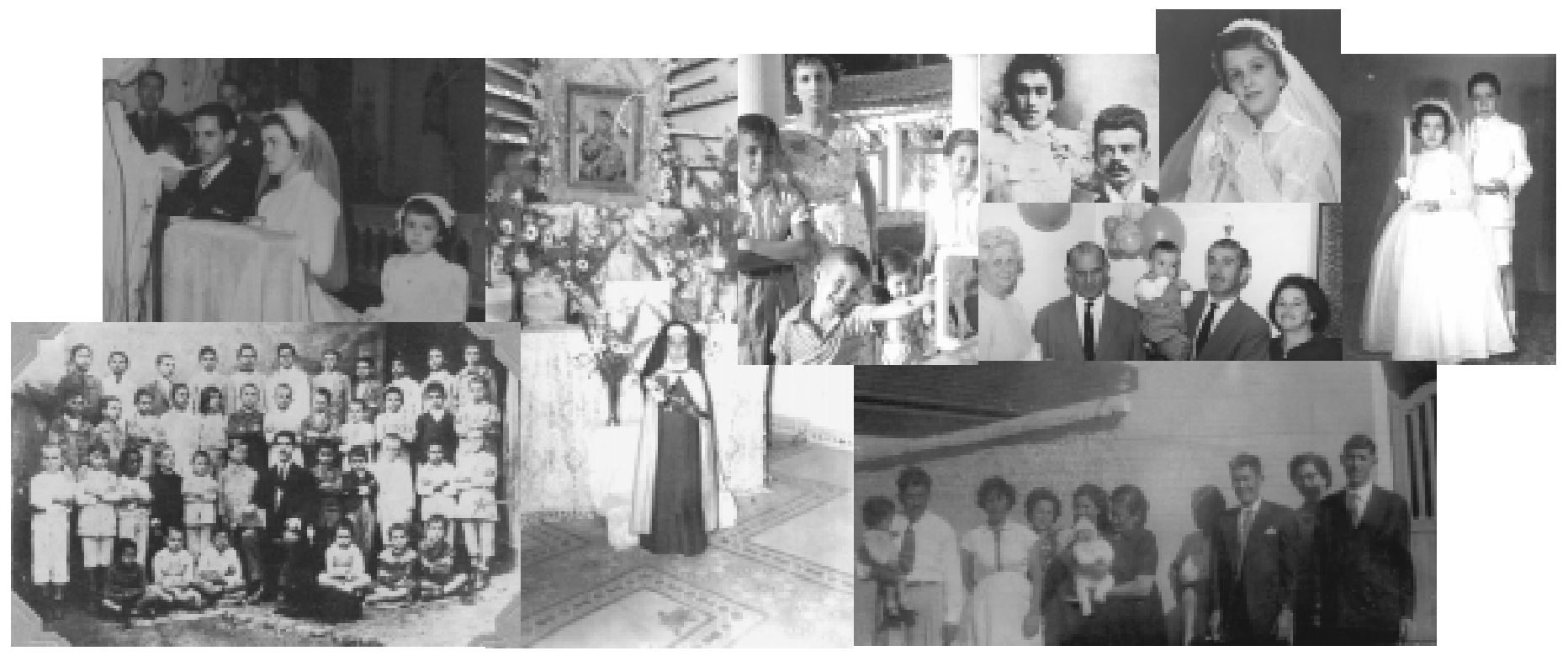


não ter "escutado o coração do bebê". Após fazer alguns exames, Mazé conta que o médico faz a curetagem, alegando que o feto estava morto. Mazé conta: "Com tudo isso minha vida era muito sofrida. Mas eu aceitar Jesus foi muito difícil, porque eu era muito dura, não sei...”. Continuando sua busca de concretizar o projeto de maternidade, ela faz de tudo para engravidar. Chega, então, o dia da "benção" recebida por Mazé.

Neste dia eu estava muito aperreada com meu marido, porque tinha visto ele com outra mulher no ônibus. Atravessei a rua quase cega de chorar, ia para casa da minha mãe. No meio da praça ali em frente estava tendo um culto. Eu parei e fiquei chorando e olhando a pregação do irmão. Sentia que tudo que ele dizia era comigo. $\mathrm{O}$ sol na cabeça, eu não tinha comido nada. Fui sentindo uma ausência.... uma coisa estranha, até que eu cai ali mesmo e não lembrei de mais nada. Já acordei na Igreja do outro lado da praça, com muitos irmãos me acolhendo. Foi quando me levaram para o Posto (de Saúde) aqui. Então a médica lá me fez umas perguntas e falou “olha, eu tô achando que você está grávida, vamos fazer o exame para confirmar'. Naquele momento eu senti que fui tocada por Jesus, senti que tinha sido agraciada com um verdadeiro milagre em minha vida. Sabia que o exame ia ser positivo, porque aquilo tinha sido um sinal do céu. Então aceitei Jesus e entreguei meu coração em suas mãos.

O que este "caso" nos diz a respeito da relação entre religiosidade, família $e$ saúde? O que nos conta acerca da visão de mundo dos urbanos pobres? $\mathrm{E}$ sobre o uso que esta população faz dos serviços de saúde em atenção básica nos bairros de periferia? Como um profissional de saúde que atende cotidianamente mulheres, muitas das quais evangélicas, se posicionaria diante do "caso"? Antes de prosseguir a leitura, proponho ao leitor(a) que reflita sobre estas questões. Pois, em parte, é com base nelas que este artigo é construído.

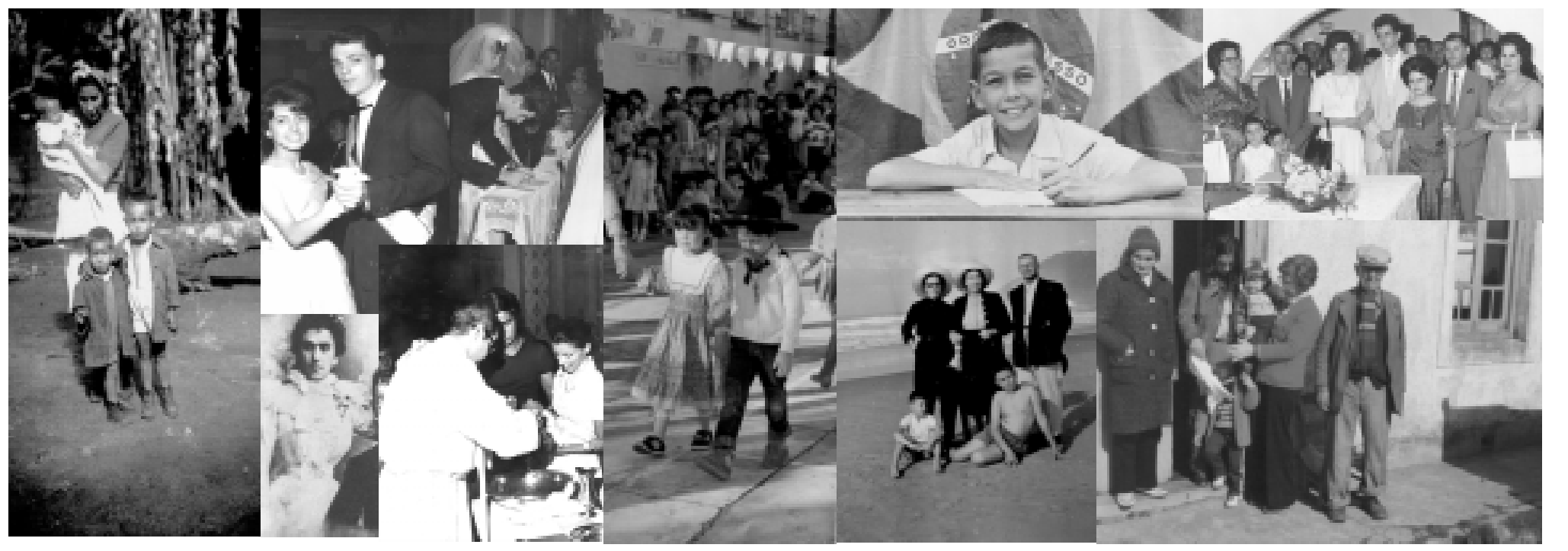


A complexa, mas já reconhecida dinâmica estabelecida entre as instituições família e religião no contexto da sociedade brasileira vem sendo traduzida por gerações de cientistas sociais (Freyre, 1997; Aubrée, 1985; Machado, 1996). Todas as transformações pelas quais atravessa a religião em nossa sociedade projetam reflexos sobre a família, ao mesmo tempo em que as mudanças que percorrem o universo familiar brasileiro incidem em vários campos do social e, entre eles, a religião. Assim, se, enquanto locus fundante da socialização, a família é uma das grandes responsáveis pela manutenção e reprodução da religião, esta, por outro lado, enquanto agente regulador e normatizador da sexualidade e reprodução, é um dos principais sustentáculos da família. Isto sem falar, é claro, no aspecto regulador moral do comportamento individual e coletivo que a religião proporciona.

Além da imbricada relação institucional, um outro e tão importante aspecto atualiza a relação entre estas esferas. Trata-se, como no "caso" relatado por Mazé, da adesão voluntária dos indivíduos a um sistema de crença e prática religiosa com a conseqüente ruptura com a própria biografia e a adesão a novos valores, modelos comportamentais e visão de mundo, em dissonância com a religião professada pela família. É sobre esta estreita relação estabelecida entre religiosidade individual professada $e$ relações familiares no contexto da sociedade brasileira e, especificamente entre os urbanos pobres, que trata este trabalho.

Num primeiro momento, e com base na produção sócio-antropológica dos campos da família urbana pobre e da religiosidade popular, procuro construir marcos que auxiliam na reflexão da interface entre família $e$ religião na atualidade. Em seguida, apresento resultados de uma pesquisa de caráter qualitativo com 15 famílias do bairro, abordando especificamente o tema planejamento familiar. Trata-se de um aspecto de uma pesquisa mais ampla que pretendeu apreender os motivos da conversão religiosa, as tensões produzidas na dinâmica familiar e as estratégias de superação tomando como base o comportamento reprodutivo ${ }^{2}$. Por fim, e a partir deste material empírico, volto-me para o diálogo com a Saúde, tratando dos serviços oferecidos e da relação estabelecida entre os profissionais de Saúde e os usuários.

\section{Problematizando a conversão e o trânsito religioso em famílias pobres}

A literatura antropológica que trata das relações cotidianas e familiares entre as camadas populares reconhece a cultura das classes trabalhadoras urbanas $^{3}$ como portadora de uma racionalidade própria. Inúmeros estudos têm procurado discernir seus traços mais pertinentes e sua lógica mais profunda (Duarte, 1986; Sarti, 1996).

O recorte deste trabalho sobre a especificidade cultural das populações urbanas pobres ${ }^{4}$ assenta-se sobretudo nos trabalhos de Duarte (1986). Apoiado em Dumont (1993), Duarte acolhe a idéia de que existem duas grandes matrizes culturais presentes nas sociedades contemporâneas. De um lado, a matriz dominante que teria como referente o individualismo; $e$ $\mathrm{a}(\mathrm{s})$ outra(s), dominada(s), que possui(em) uma lógica mais holista. À maneira do autor, não reforço uma possível argumentação que sugere que
${ }^{2}$ A pesquisa sobre comportamento reprodutivo apresenta também dados sobre virgindade, escolha de parceiros, aborto $e$ criação de filhos (ver Couto, 2000).

${ }^{3}$ Tomamos a expressão como sinônimo de outra: urbanos pobres. Ambas designam o universo de categorias sociais que se encontram numa posição subordinada ou inferior na sociedade de classes, moderna e urbana.

${ }_{4}^{4}$ Mesmo recorrendo à categoria "urbanos pobres", chamamos atenção para a necessidade de evitar considerar estes como uma categoria homogênea.

Entendemos que um

dos grandes desafios

das Ciências Sociais foi o de quebrar ou

desconstruir a noção

"monolítica" de pobre e pensar a pluralidade e diversidade interna à categoria, em termos de gênero, classe, raça etnia, idade, religião etc. 
${ }^{5}$ Esta problemática foi extensamente trabalhada por Bourdieu (1982) e sua perspectiva também informa o recorte deste trabalho.

${ }^{6} \mathrm{O}$ modelo sincrético no Brasil persistiu até o início dos anos 70 sobretudo pelo forte peso institucional do catolicismo. Os protestantes históricos, dado o reduzido número, não impunham significativas ameaças ao catolicismo, enquanto os simpatizantes das religiões afrobrasileiras não se desvencilhavam de sua identidade católica, preferindo justapor os dois sistemas religiosos. os urbanos pobres possuem uma cultura específica e de todo separada do modelo dominante. Ao contrário, trabalho com a noção de que ela mantém uma relação bastante peculiar de leitura de mundo em que há uma interface direta e constante com os pressupostos centrais da modernidade. Assim, afirmar a positividade dos urbanos pobres significa não submetê-los ao olhar da falta, mas tomá-los como portadores de um sentido que, dado seu traço próprio, destoa das marcas do universo da modernidade, aqui especialmente pensada como aquela que dá suporte aos referentes da classe média. Em outras palavras, ao reconhecer o potencial desigual que as classes têm para difundir e legitimar sua visão de mundo, compreendo que a relação entre elas se dá num intricado jogo de forças em que mesmo os mais despossuídos operam na afirmação e recriação de suas diferenças ${ }^{5}$. $O$ quadro resultante que se apresenta para o analista é, senão desalentador, bastante complexo. Isto porque exige uma abordagem que permita, ao mesmo tempo, compreender as múltiplas interseções entre os esquemas culturais na forma como eles são atualizados pelas pessoas em seus modos de vida cotidianos $e$, também, o reposicionamento das fronteiras sociais característico do processo de mudança cultural em andamento.

Com respeito ao universo das práticas religiosas em nossa sociedade, a idéia de sincretismo e mistura religiosa liga-se à análise da própria noção de identidade nacional, que foi construída em termos de um sincretismo étnicoracial-religioso. Assim, não é de estranhar que diferentes e mesmo temporalmente distantes interpretações da identidade nacional brasileira, tal como a de Gilberto Freyre (1997) e a de Roberto Da Matta (1989), tenham ressaltado essa base tríplice e de caráter conciliatório. Mas as transformações que vêm sendo operadas a partir da década de setenta impõem a necessidade de rever a já arraigada noção de sincretismo em nossa sociedade. A entrada do fenômeno pentecostal em cena vem transformar o panorama religioso nacional. Caracterizando-se por um tipo de religiosidade que requer comprometimento forte com o grupo de referência $e$, portanto, uma identidade exclusiva, as igrejas pentecostais multiplicam-se aos milhares, sobretudo entre as camadas populares, durante as quatro últimas décadas, promovendo a transformação de um modelo sincrético para um modelo plural do tipo "mercado religioso" (Mariz e Machado, 1998) ${ }^{6}$.

Cada vez mais a opinião pública e mesmo reconhecidos estudiosos da religião defendem a tese de que a religião que se professa hoje não é mais aquela na qual se nasce. A compreensão é a de que as mudanças operadas no campo religioso nas últimas décadas $e$ a conseqüente entrada $e$ estabelecimento em nossa sociedade do "mercado religioso" promove um fenômeno de trânsito individual, livre e quase ininterrupto. Mais de um quarto da população adulta da região metropolitana de São Paulo professa hoje religião diferente daquela em que nasceu, são convertidos, muitos tendo experimentado sucessivas opções. Para alguns, a mudança de religião não é vista mais como um drama pessoal e tampouco familiar.

Não discordo da percepção deste fenômeno de trânsito religioso intenso, mas questiono as variações e os significados específicos para homens, mulheres, jovens, adultos, solteiros, casados, viúvos, do meio rural $e$ 
urbano... em suas famílias. Assim, opto por focalizar a análise numa outra, $e$ também importante, referência: o reconhecimento da conexão entre a experiência religiosa vivenciada, o estilo de vida particular de quem a adota $e$ as intercorrências na vida familiar. Esta percepção liga-se à compreensão da afiliação religiosa como um processo que implica não apenas a aderência a um sistema de crenças, mas também um comprometimento com o grupo que sustenta estas crenças. Ainda que a conversão possa ser entendida $e$ publicamente expressa em termos do relacionamento homem/divindade, também envolve modificações no intercâmbio social $e$, portanto, nas relações familiares. E é sobre isto que tratarei a seguir, especialmente quanto ao comportamento reprodutivo das famílias com pluralismo religioso.

Sexo e reprodução: novos valores religiosos nas famílias pobres?

Existe um consenso entre os historiadores de que a tradição sexual cristã foi marcada até meados do presente século por uma percepção fortemente negativa da sexualidade. Associada a uma percepção restritiva desta, observa-se o tratamento desigual aos parceiros sexuais, cabendo à mulher subordinar-se ao homem, cabeça do lar e da família. A doutrina católica elabora - sobretudo a partir do século V e por obra de Santo Agostinho - um discurso bastante nítido quanto às práticas sexuais e aos métodos contraceptivos: a legitimidade destes faz-se mediante o vínculo entre vida sexual e reprodução. Os primeiros reformadores - tanto Lutero como Calvino -, absorveram tais normas e códigos e, ao seguir as concepções éticas católicas, aceitaram as limitações impostas ao uso dos meios contraceptivos.

Mas esta orientação original protestante vem sofrer modificações, sobretudo durante o século XIX, e culmina com a liberalização dos meios contraceptivos nos anos trinta pela maioria dos teólogos e pastores evangélicos. Com isso, os meios artificiais de contracepção deixaram finalmente de estar vinculados ao sexo "ilícito" e "pecaminoso"; sendo a decisão do seu uso transferida à esfera médica e ao casal (Machado, 1996).

Originalmente dissidentes das igrejas históricas, os primeiros grupos pentecostais em nossa sociedade $e^{7}$ caracterizavam-se pela rejeição de traços significativos da cultura brasileira: o futebol, a cerveja, o carnaval e os cultos afro-brasileiros freqüentados por católicos pouco praticantes (Machado, 1996). O forte vínculo com evangélicos fundamentalistas norte-americanos que

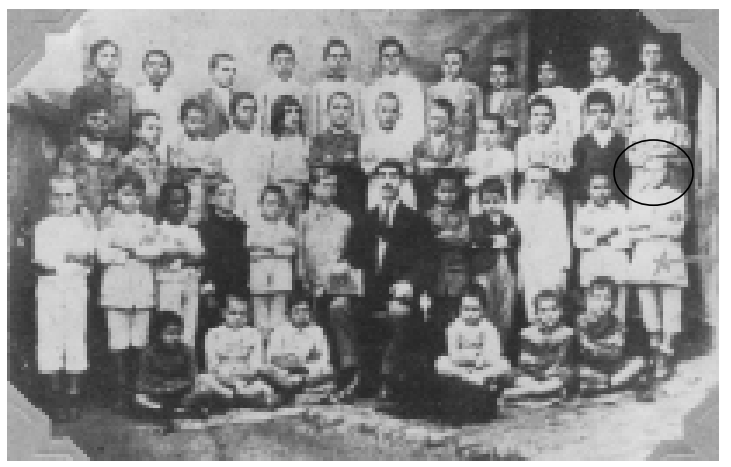
reforçavam a repressão ao corpo e à sexualidade, fizeram alguns estudiosos caracterizá-los como fundamentalistas, opositores da separação entre sexo $e$ reprodução e, conseqüentemente, contrários às práticas contraceptivas e às formas de planejamento familiar. Assim, para o público em geral e segundo os primeiros estudiosos do tema, um dos principais traços constitutivos da

\footnotetext{
7 Segundo Freston (1994), o pentecostalismo no país pode ser visualizado em três grandes ondas. A primeira, na década de 10 , com a chegada da Congregação Cristã $e$ da Assembléia de Deus; a segunda, nos anos 50 e 60, com a Igreja Quadrangular, Brasil para Cristo e Deus é Amor, e a terceira, ao final dos anos 70 , com a Igreja Universal do Reino de Deus.
} 
${ }^{8}$ Foram realizadas

entrevistas individuais com os membros do casal em dez famílias com pluralismo religioso (católicos e pentecostais), representativas do arranjo de família plural mais freqüente no bairro; e em cinco famílias de pentecostais, como grupo controle. identidade do "crente" seria a defesa da castidade para solteiros e não casados, a fidelidade conjugal, a sobriedade nos trajes, a oposição à vaidade (feminina e masculina) e a não separação entre sexo e reprodução.

Mas o universo evangélico não é homogêneo. Ao contrário, caracteriza-se por uma dispersão de posições ideológicas com múltiplas orientações muitas vezes antagônicas - no que diz respeito a sexualidade e reprodução. Se as denominações possuem o traço comum do apelo à emoção e à valorização das interações corporais, distinguem-se em função da rigidez moral no campo da sexualidade e da reprodução. Assim, a Assembléia de Deus pode ser considerada como a mais tradicional no continuum do tradicionalismo para o liberalismo, estando a Igreja Universal do Reino de Deus no último pólo deste continuum (Machado, 1997). Portanto, é necessário reconhecer a pluralidade de orientações dirigidas por estas igrejas, assim como as variações quanto à adequação do estilo de vida pessoal ao discurso religioso em torno da sexualidade e reprodução por homens e mulheres em suas diferentes etapas do ciclo de vida pessoal $e$ familiar. Partindo desta perspectiva, ao tratar dos aspectos relativos à reprodução considero as reformulações na identidade dos sujeitos e, por isto, o "tempo de conversão" como fator de grande importância.

O exame do comportamento reprodutivo com base nas entrevistas em profundidade realizadas com os homens $e$ as mulheres no bairro do Ibura ${ }^{8}$ pôde ajudar a desvendar a diversidade de valores e comportamentos dos pentecostais quanto ao planejamento familiar, ao mesmo tempo traz à tona algumas particularidades do universo simbólico dessas famílias pobres.

Um dado que chama bastante atenção é a preeminência do núcleo familiar. O todo relacional representado na família exprime-se por meio de uma divisão de trabalho entre os gêneros que é, ao mesmo tempo, moral e familiar. Neste contexto, os atributos de gênero são tomados a partir de uma complementaridade hierárquica. Ao masculino está destinado uma maior exterioridade e a associação com o que é de domínio público, dimensão consolidada na esfera do trabalho. De forma complementar a este, emerge o privado, espaço associado à interioridade e ao domínio do natural, portanto, espaço feminino. Ser homem significa, em termos ideais, exercer com firmeza o papel de provedor material e moral, o que garante o respeito por parte do grupo e perante o universo social que o rodeia. À mulher, em contrapartida, está associado o desempenho de tarefas como cuidar da casa, do marido e dos filhos. O estudo de Paim (1998) mostra que os cuidados com a contracepção, gravidez e manutenção da prole são desempenhados pelas mulheres e considerados não como fruto de um processo de socialização, mas como aptidões próprias à natureza feminina.

Nas entrevistas com homens e mulheres pentecostais também chama atenção o fato de que a tradicional vinculação do sexo com a reprodução não é primordial. Como já assinalou Machado (1996) e Fernandes (1998) em outras pesquisas, as mulheres preferem identificar sexo com amor $e$ prazer. Se é possível perceber aí um deslocamento no sentido de uma visão menos tradicional para uma outra voltada aos valores correntes na sociedade como um todo, reconhecer-se que para essas mulheres a dimensão da satisfação sexual ainda está atrelada a uma ordem moral cristã que 
canaliza a sexualidade para o casamento.

Quanto ao relato de suas vivências no campo da sexualidade $e$ reprodução, a maioria das mulheres mostraram-se dispostas a falar, com fluência e tranquilidade, sobre sexo e intimidade. Tinham muito a contar sobre as histórias afetivas/sexuais de suas vidas, que sempre incluíam temas como namoro, casamento, gravidez e nascimento de filhos. Entretanto, as descrições destas situações conectadas à participação masculina foi bem mais reduzida, descritas sem minúcias. Ainda no campo da sexualidade e reprodução foi recorrente a preocupação com a satisfação sexual do homem/companheiro. Ao considerar o homem como um ser diferente e regulado por instintos estranhos à natureza feminina, as mulheres redirecionam a preocupação com sua própria sexualidade para a sexualidade do companheiro, o que denota o cuidado em corresponder às expectativas, no sentido do cumprimento de suas obrigações maritais. $O$ sexo e a vida afetiva do casal foi compartilhado pelos homens com uma absoluta parcimônia. Numa certa medida, para os homens, pentecostais ou não, sexo não se discute, não é algo de que se fale no intuito de conferir significação própria, pois seu significado está preso a uma lógica naturalista que o coloca no lugar daquilo que se faz e não se cogita.

Tratando do tema planejamento familiar propriamente dito, tomo como ponto de partida o uso de métodos contraceptivos e apresento um dado revelador: a grande maioria dos casais relataram fazer ou ter feito uso de métodos artificiais durante a vida, especialmente, a pílula. Mas aqui cabe identificar algumas variáveis de cunho religioso e familiar que possibilita uma compreensão da disseminação do uso de métodos artificiais de forma mais detalhada. O fator "tempo de conversão" é fundamental para perceber a influência da ideologia secular nos indivíduos. A grande maioria das mulheres atualmente evangélicas promoveram dissidência religiosa tornando-se pentecostais após o casamento, assim, não é de estranhar que tenham feito uso de métodos artificiais. Mas o que é interessante perceber é que, mesmo após a conversão, e sobretudo por parte daquelas que não conseguiram trazer para sua igreja/religião seus maridos, o uso de métodos artificiais permanece. Apenas uma mulher pentecostal casada com homem não evangélico apontou sua opção de não fazer uso de métodos contraceptivos artificiais, referindo tal atitude a sua opção religiosa:

\footnotetext{
Olhe, no tempo que eu casei, logo depois eu me converti. Tinha um ano de casada. Por ele (marido) a gente só tinha um casal de filhos. E eu disse que não ia tomar remédio não. Também porque eu já era evangélica, né? Aí terminei tendo cinco filhos, para mim foi uma benção. Mas ele arengava muito, dizia que não queria mais ver menino em casa.... Quando ele menos esperava eu engravidava, né? Foi muito conflito...

(Dona Diva, 50 anos, casada, Assembléia de Deus).
}

No grupo de mulheres cuja faixa etária é dos trinta aos 59 anos, e que durante algum tempo fizeram uso de métodos artificiais (11 mulheres ao todo), a maioria (sete) declarou ter recorrido à laqueadura. Embora tal 
opção não seja a preferencial por parte das igrejas evangélicas no discurso dos seus oficiantes, todas as que recorreram a este método disseram que se sentiam "confortáveis" com a decisão. O tempo de participação na igreja, neste sentido, parece não ter uma influência importante na tomada de atitude das mulheres, já que quatro das sete optaram por este procedimento após a conversão. Isto coloca sob suspeita a relação, muitas vezes considerada causal, entre pertencer a um grupo religioso que busca a "santificação" - daí a necessidade de observância às regras estabelecidas pelas autoridades religiosas - $e$ a

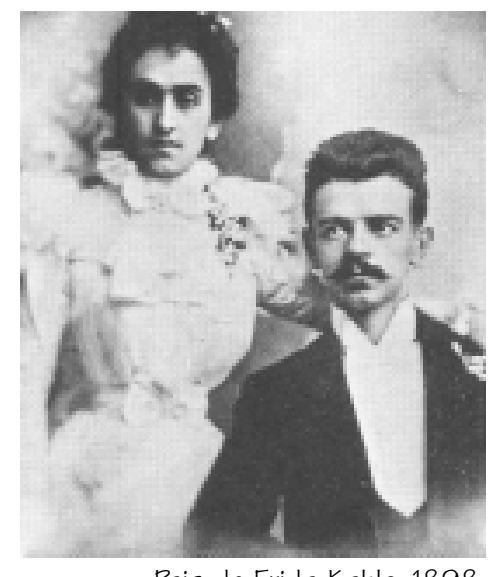

Pais de Frida Kahlo, 1898 opção por esta forma "definitiva" de planejamento familiar.

Também a "trajetória de vida" tem um peso importante na conformação deste quadro. A opção pela esterilização foi relatada após uma longa caminhada e tentativa de adequação com o método que todas referem ter feito uso em algum momento de sua vida reprodutiva: a pílula.

Eu tomei anticoncepcional por dois meses. Apesar do primeiro mês eu não me dei com o anticoncepcional. Eu não me dei aí o médico passou outro. Mas não me dei. Aí eu fiz tabela e nela a menina veio. Eu não posso tomar anticoncepcional. O nervo atacava demais e saia manchas roxas no corpo; e podia me matar atingindo o coração. $\mathrm{O}$ médico ficou com medo e suspendeu no ato. (Telma, 38 anos, Casada, Igreja Congregacional)

Quando eu tive Juli eu usava pomada. Não me dei com comprimidos, ficava nervosa, com enjôo e muita dor na cabeça. Aí passei para pomada. Era uma pomada tão chata, que você tinha que colocar antes do sexo; aí se esquecesse era fatal. Aí ele disse: "bota logo essa pomada para quando eu chegar...", Mas só podia botar três minutos antes; não podia botar muito tempo, porque senão ela escorria. Aí a gente não agüentou sete meses.

(Ione, 39 anos, casada, Igreja Congregacional)

O conjunto dos entrevistados (homens e mulheres) reconhecem os preceitos morais e éticos evangélicos quanto ao tema em questão. Dizem que o uso dos métodos naturais é preferível ao uso de métodos artificiais. Contudo, muitos se apóiam no próprio discurso orientador dos pastores de suas igrejas para minimizar uma possível "culpa" ou sensação de "transgressão das orientações evangélicas". Vale ressaltar que os discursos dos pastores estão sobretudo atrelados a uma orientação para os casais que estão começando a vida. Os noivos que pretendem casar nas igrejas evangélicas passam por período de conversas e palestras, acompanhados de perto pelo pastor, o qual faz preleções sobre a constituição das famílias cristãs, a sexualidade vivida entre o casal cristão e os deveres/obrigações dos cônjuges no sentido de viver o amor e constituir a família "em Cristo". 
Os dados sobre o uso de métodos contraceptivos nos remete às diferenciações de gênero em nossa sociedade. Alguns estudos mostram o quanto é importante incorporar os homens nas pesquisas sobre Saúde Reprodutiva, isto porque é inegável a influência masculina na determinação das formas como as mulheres conduzem sua vida e saúde reprodutiva, destarte os homens colocarem-se à margem das discussões sobre o tema, seja no âmbito privado ou público (Villa, 1997). Neste sentido, e tomando gênero como categoria de análise, busquei compreender as representações $e$ atitudes dos homens entrevistados acerca desta temática. Em primeiro lugar, ficou claro que a participação dos homens é ainda bastante tímida no que se refere ao uso de métodos contraceptivos, cabendo às mulheres arcar com tal responsabilidade. Assim, apenas um entrevistado fez referência a sua participação no planejamento familiar como algo do qual se orgulhava. Entretanto, questões práticas fortemente relacionadas estiveram associadas com a decisão: o acesso ao procedimento - pois ele trabalha no hospital da marinha e, conhecendo a equipe médica, não esteve sujeito a qualquer ônus $e$, segundo, pela não adaptação à pílula por sua mulher que foi aconselhada pelo médico a parar o uso. O método masculino mais generalizado $e$ difundido, a camisinha, não tem uma aceitação boa entre os nossos informantes, fato reconhecido pelos próprios homens e sobretudo pelas mulheres. Tal recurso não é o primeiro e tampouco visto como satisfatório para os homens, que dizem não se sentir à vontade com o uso. E mais, o uso se dá apenas nos casos em que a mulher se vê impossibilitada de tomar contraceptivos hormonais ou ainda não conseguiu o acesso a laqueadura. Assim, de uso excepcional e temporário, a camisinha é descartada enquanto contraceptivo no surgimento de qualquer outro meio de contracepção a ser utilizado pelas esposas.

De forma resumida, e como os estudos no campo da Saúde Reprodutiva em geral mostram, a baixa participação masculina não implica num posicionamento autônomo e independente das mulheres. Ao contrário, reforça a lógica da "responsabilidade solitária" da mulher, mesmo que com forte pressão masculina no controle de sua vida reprodutiva. Com isto, temse o reforço de uma das bases da desigualdade de gênero: a regulação e a baixa autonomia da vida reprodutiva das mulheres.

As questões acerca do número ideal de filhos, idade ideal para ter o primeiro filho e espaçamento entre as gestações contribuíram para o melhor entendimento sobre a dinâmica familiar entre os gêneros perpassada pela afiliação religiosa. Um dado interessante que sobressaiu de todas as entrevistas realizadas foi o desejo do homem em, logo após a união, ter o primeiro filho; e, claro, que a escolha é por um filho varão. Assim, mesmo entre os poucos homens pentecostais que entrevistamos (três) e que na época do casamento receberam orientações pastorais para que aguardassem pela melhor estabilidade financeira e emocional do casal, dois falaram sobre o desejo de ter o primeiro filho o quanto antes, chegando a cobrar das esposas "uma parada" nos anticoncepcionais. Para Edvaldo, quarenta anos, da Assembléia de Deus: "quando um homem casa, ele logo quer constituir uma família. E você sabe, a família só está constituída quando aparece o primeiro filho. Sempre pedi a Deus que o primeiro fosse um varão, e foi". 
Todavia, a maioria dos homens após ter o primeiro filho passa a questionar a necessidade de o casal ter outros. Enquanto o número ideal de filhos para os homens foi dois, o número ideal para grande parte das mulheres foi quatro (geralmente dois casais), o que aponta para uma grande disparidade. Causou-me surpresa alguns relatos femininos que giraram em torno dos conflitos entre o casal devido à discordância sobre o número de filhos. Para Sílvia, 52 anos, da Assembléia de Deus, chegar a um acordo quanto ao número ideal com o marido, também da Assembléia de Deus, não foi fácil.

Bom, quando eu me casei logo, em 68, eu passei dois anos evitando. Que a gente não queria filho logo porque a gente não tinha uma casa. Foi tempo que eu fiquei grávida de André..., aí de André para Aninha tivemos cautela. Quando foi... dos outros três já desembestou, desencarrilhou (risos). Mas é que eu... meu marido só queria um casal. 'Um casal só!', ele vivia falando. E eu dizia: 'não, filho, mas um casal é tão pouco, eu quero mais, pelo menos uns quatro'. Eu fiquei tentando sem ele saber, ai nasceu mais um, outro, e outro. E ele sempre se pegava em briguinha comigo por isso.

O mesmo acontece com Dona Diva, cincoenta anos, casada, Assembléia de Deus:

Tive o primeiro aí o marido falou: 'tá bom, né, só mais um'. Aí pronto, era ele quem evitava. Na hora H... fora. Só que eu queria mais filhos. Até a segunda não, mas na terceira, foi luta. Que ele não queria aceitar, não queria aceitar. E eu não tomei remédio, não queria tomar remédio... aí hoje a menina ela é muito assim... ela nunca soube, mas ela foi rejeitada. No começo logo que nasceu a bichinha... Depois ainda tive mais dois meninos nessa luta danada.

Se não há acordo quanto ao número ideal de filhos entre os casais, o fator da afiliação religiosa evangélica parece não ter comprometido este aspecto da dinâmica familiar. Ao contrário do que o senso comum postula, o vínculo religioso evangélico não teve influência na

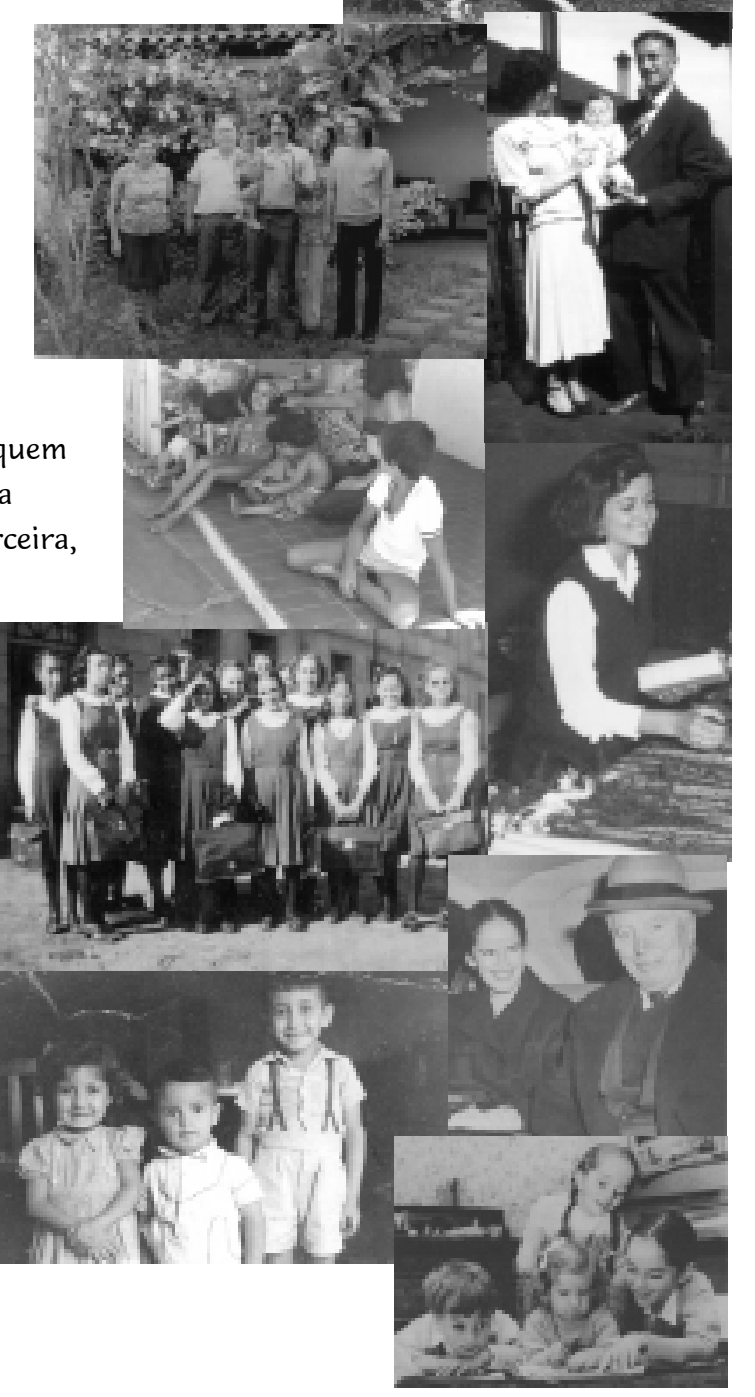

fevereiro, 2001 
configuração de um número ideal de filhos, isto sobretudo para os homens. A grande maioria dos entrevistadas reconsiderou, frente à instabilidade financeira que vive, algumas passagens bíblicas, evidenciando que a leitura literal da Bíblia não deve ser tomada como regra. A interpretação deste livro sagrado, portanto, tende a ser mais histórica que fundamentalista, quando a questão é o planejamento familiar. Segundo Sr. José, casado, 35 anos, da Igreja Missão Evangélica Pentecostal,

\footnotetext{
Quando o Senhor disse 'crescei, multiplicai e enchei a terra', faz alguns milhares de anos... E qualquer mente, por mais desprovida de bom senso que possa ser, há de perceber que, realmente, foi uma escritura de um tempo já distante. Mesmo sabendo que a palavra de Deus permanece para sempre, muitas coisas foram ditas, faladas para uma outra ocasião.... Você tem que ver isso. Hoje temos na muita, muita gente. Quer dizer... a situação não é fácil. Agora a igreja, nós o povo de Deus, eu diria que é um consenso. Todo método é válido, tá certo? Contanto que... logicamente esses métodos anticoncepcionais não venham trazer dano para a saúde das mulheres, o que danifica sua saúde é burrice, né? Então quem vai usar a coisa deve ter o máximo de cuidado possível.
}

\section{Diversidade e diálogo com a Saúde}

A interface entre Saúde e religiosidade nos grupos populares vem há muito constituindo um campo que hoje já é referência para as Ciências Sociais, sobretudo no domínio da Antropologia no que se denomina Antropologia da saúde-doença ou Antropologia Médica. O grande foco de análise neste campo tem se formado em torno dos aspectos rituais dos sistemas de cura das religiões populares, especialmente o catolicismo popular, as religiões afrobrasileiras e, mais recentemente, o pentecostalismo. Ambos, cientistas sociais e profissionais da Saúde, reconhecem que a cultura religiosa brasileira dispõe de uma pluralidade de cultos que oferecem serviços de cura, cada um deles contando com ricos repertórios de símbolos e imagens que exprimem diferenciadas visões de mundo. O reconhecimento desta pluralidade reinante, como se sabe, tem freqüentemente motivado muito mais antropólogos, que concebem a doença como parte de um contexto sócio-cultural ampliado, e menos o saber médico, cujas explicações vinculamse a um caráter mais reducionista, em que o doente é despersonalizado (Rabelo, 1998). Mesmo na vertente antropológica que trata das religiosidades populares como sistemas de cura (Minayo, 1998; Rabelo, 1998) pouca atenção tem sido dirigida à expressão cotidiana que a nova visão de mundo imprime aos indivíduos, sendo a religiosidade tomada pela resposta que oferece às aflições no campo da Saúde, muitas vezes em seu caráter pontual. Assim, privilegia-se o aspecto sincrônico da experiência de cura em seus efeitos momentâneos em detrimento de uma abordagem com foco na diacronia.

A indicação, neste trabalho, da possibilidade de diálogo entre a 
${ }^{9}$ Uma avaliação dos serviços de saúde do bairro foi realizada por uma equipe multidisciplinar com a qual mantive estreito contato na ocasião, no âmbito do projeto de avaliação sócio-cultural de saúde no Ibura (Scott, 1996).

${ }^{10}$ Sobre esta caracterização ver Couto (1996) e Scott (1996).

${ }^{11}$ Além da pesquisa anteriormente citada (Scott, 1996), foram realizadas

recentemente dez entrevistas com profissionais de saúde (seis gerentes e quatro médicos) sobre ações de saúde reprodutiva existentes e sobre o uso que a população faz dos serviços (ver Couto, 2000). religiosidade e a Saúde, se dá sob um outro enfoque: o de perceber até que ponto a multiplicidade de sistemas religiosos que permeia o universo cultural dos urbanos pobres, oferecendo distintas visões de mundo, oferecem possibilidade não apenas circunscritas ao encontro momentâneo de cura das aflições no campo da Saúde, mas conformam novos valores $e$ padrões comportamentais que, de forma duradoura, são incorporados pelos indivíduos, implicando numa "domesticação" do corpo com conseqüências para a saúde. Sob este enfoque, que tem como ponto central o crescimento do Pentecostalismo em áreas de pobreza, é possível levantar questões que ajudam a pensar a relação instituída entre população e serviços de saúde, assim como para refletir como os serviços de saúde planejam e orientam ações voltadas para suas clientelas.

O acesso que os moradores do Ibura têm aos serviços de saúde do bairro pode ser descrito de forma similar para inúmeras outras áreas de periferia de grandes cidades. Todos os serviços de saúde existentes no bairro ${ }^{9}$ constituem-se em centros de atenção primária à população, com exceção de uma policlínica que apresenta um perfil diferenciado com serviço de pronto atendimento e atendimento ambulatorial. O acesso aos Postos de Saúde é relativamente facilitado devido à distribuição espacial das seis unidades básicas existentes, o que gera um certo "trânsito" ou "flutuação" da população na busca das ações de saúde oferecidas nestes serviços. Nos Postos de Saúde, o quadro funcional é bastante homogêneo, variando apenas em termos de número de profissionais e tempo que destinam ao atendimento. A equipe multiprofissional é formada por ginecologista, clínico, pediatra, enfermeira, auxiliar de enfermagem, odontólogo e agentes comunitários de saúde, que variam de quatro a seis em número.

Não cabe aqui descrever o conjunto das ações de saúde oferecido à população local ${ }^{10}$, mas, dadas as considerações anteriores sobre o tema planejamento familiar, torna-se interessante apontar as configurações gerais dos programas e ações desta área existentes na localidade. As ações de planejamento familiar são, no geral, conduzidas por enfermeiras que fazem palestras para grupos diferenciados de mulheres. Algumas são mães de filhos pequenos que fizeram o acompanhamento pré-natal na unidade de saúde e, no momento, buscam auxílio para evitar nova gravidez. Outras, mais jovens, ainda não tiveram filhos, embora tenham parceiros fixos ou estejam casadas. Estas, em reduzido número, são apontadas pelos profissionais dos serviços como desinteressadas e pouco assíduas nas reuniões de grupo e palestras. O relativo interesse deste público mais jovem, argumentam os profissionais, advém do cadastramento no programa para ter acesso aos métodos contraceptivos (camisinha e pílula) que, quando disponíveis, são repassados para as usuárias já cadastradas. Em caso de abastecimento normal, o que nem sempre é comum, estes são disponibilizados a cada 15 dias, momento que geralmente tende a coincidir com as atividades ordinárias de planejamento familiar.

Nas entrevistas e conversas informais ${ }^{11}$ com os profissionais de saúde do bairro (gerentes e médicos) sobressaiu uma preocupação geral que foi colocada em termos de uma pergunta: “como vive essa gente?" Tal questão não traz consigo uma resposta pronta ou racional. Para estes profissionais, 


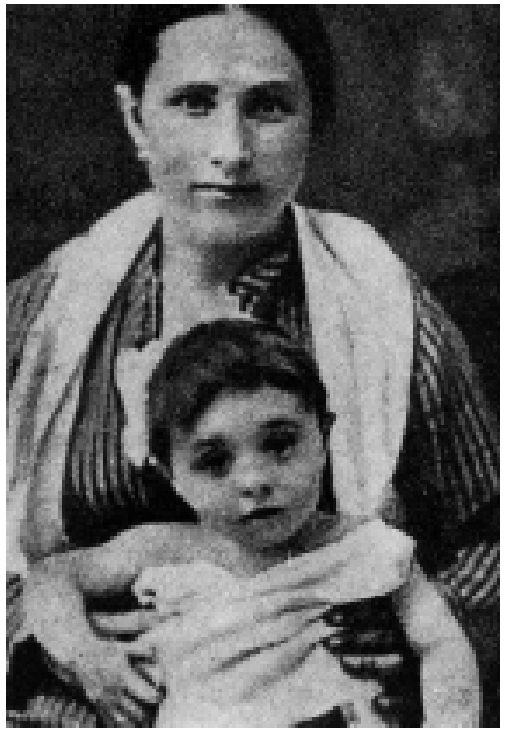

Modigliani com a ama, 1885

as duras condições que a vida imprime aos moradores do Ibura é, ao mesmo tempo, sub-humana, dada a carência de recursos que para eles são mínimos, $e$ sobre-humana, em termos de um poder de resistência à adversidade a que estão submetidos. No tocante ao planejamento familiar, uma visão antiga - para não falar ultrapassada - e quase unívoca emergiu dos relatos: a de que os pobres se reproduzem sem pensar no amanhã, sem uma preocupação racional com o contexto de carência em que vivem. Este argumento é tributado a todos, sem exceção; mas para os evangélicos soma-se uma faceta que os deixa ainda mais perplexos: "a vontade de Deus". Mas será que os "crentes"- categoria utilizada pelos profissionais de saúde, de forma ampla, para denominar as pessoas evangélicas - são todos iguais?; e mais, obedecem a uma leitura literal ou fundamentalista dos preceitos bíblicos, como acreditam estes profissionais?

A pesquisa sobre planejamento familiar realizada com as 15 famílias apontou que o universo pentecostal, a despeito de suas variações internas, tem uma atitude que pode ser considerada como liberalizante ou secular. Os dados qualitativos são referendados por estudos quantitativos e, de forma resumida, pode-se entender que para os evangélicos "Deus deu à humanidade o conhecimento científico e, por conseqüência, a capacidade de produzir métodos anticoncepcionais que devem ser usufruídos por homens e mulheres" (Fernandes, 1998, p.108). Portanto, ao acionarem o adjetivo "tradicional" de forma universal para todo o grupo pentecostal, os profissionais dos serviços constróem uma imagem "homogênea" de um dado que se espelha na realidade de forma plural. Em outras palavras, o não entendimento por parte dos profissionais de saúde, antenados numa cultura racionalista e de valores modernos/individualistas (aqui penso de forma específica nos médicos, enfermeiros e gerentes), da experiência da religiosidade pentecostal como plural e não apartada dos mesmos valores seculares e modernos, os faz reproduzir uma idéia de "cultura da pobreza" que se auto-replica a despeito da vontade das pessoas.

Neste tipo de argumentação fica de fora um aspecto - que tem sido apontado para o grupo dos evangélicos em geral - que diz respeito ao cuidado com o corpo e com a saúde. Segundo Mariz (1994b), a idéia de "libertação" é peça fundamental no discurso pentecostal. Muitos processos de adoecimentos são considerados pelos pentecostais como resultantes de uma investida externa (do diabo) e, portanto, estão associados a uma sensação de fraqueza e escravidão. A luta contra esta "força demoníaca" só tem sentido na medida em que o indivíduo se entrega a Deus. A libertação ou cura, portanto, se dá às custas de uma submissão a novas regras $e$ preceitos comportamentais, em que as "fraquezas" e os "vícios" do corpo (bebida, cigarro, comportamentos abusivos em geral) são abolidos ou reprimidos. Nesta lógica, a noção de autonomia e racionalidade convive de forma harmônica com a idéia de um mundo mágico e sobrenatural. Assim, 
ao mesmo tempo em que se tem mais uma vez referendado o propósito aqui trabalhado de que a cultura dos urbanos pobres não se constrói como um universo em total dissonância com a lógica moderna da sociedade, vê-se que traços "modernizantes" de parte destes segmentos são desconsiderados pelos profissionais de saúde em detrimento do caráter "mágico" que essa religião imporia aos seus adeptos.

Cabe discutir a "origem" da dificuldade sentida por esses profissionais em reconhecer o caráter multifacetário da realidade local e trazê-lo à prática cotidiana do trabalho. Tomo aqui dois exemplos. O primeiro diz respeito à temática da religiosidade como recurso das camadas populares para a solução de suas aflições, associadas a processos de morbidade. Para a maioria dos profissionais de saúde, a dimensão da religiosidade ou do transcendente é quase sempre escamoteada. Justificativas como "subjetividade exacerbada", "ordem do desconhecido", apenas vêm reforçar a idéia de que a diversidade presente no universo simbólico dos grupos populares sobre o processo saúde-doença não se ajusta aos cânones de cientificidade da prática médica, ou mesmo dentro da pesquisa acadêmica em Saúde Pública. Por certo que a visibilidade do fenômeno pentecostal veio impor novas questões sobre pertencimento religioso para profissionais de saúde em face da nova configuração de uma clientela em expansão (os "crentes" ou pentecostais). Até pouco tempo, a religiosidade popular de maior visibilidade para os profissionais de saúde era a afro-brasileira, sendo o catolicismo popular considerado apenas como uma forma excêntrica $e$, de resistência no meio urbano, de uma cultura religiosa mais arcaica. Se compararmos a noção de pertencimento religioso para pentecostais $e$ adeptos de cultos afro-brasileiros, veremos uma significativa diferença. Como aponta Fernandes (1998), marcados por um estigma impresso pelo mundo da religião "oficial", muitos dos adeptos dos cultos afro-brasileiros não chegavam a romper com a identidade católica, preferindo lidar com o duplo pertencimento; já os pentecostais caracterizam-se por construírem uma identidade religiosa exclusiva. A visibilidade de opção religiosa é expressa de forma reiterada por um proselitismo, por vezes exacerbado; uma nova e rígida forma de regulação do corpo, da sexualidade e da saúde é acionada na demonstração clara do rompimento com "o mundo" (bebida, cigarro, prazeres sexuais considerados ilícitos etc.) (Mariz, 1994b; Machado, 1996). Talvez essas características, ao invés de sugerir novas aproximações dos profissionais de saúde com os sujeitos, o que poderia implicar na otimização de suas ações de cuidado, tenha resultado num afastamento maior desse "outro" (distante culturalmente) tão "próximo" (localmente).

Tem-se instaurada uma visão do "outro" como "diferente", mas, ao mesmo tempo, homogêneo ("crente"). Implicações desta lógica podem ser observadas não apenas no trabalho cotidiano na atenção primária em saúde, mas também nos planejamentos de programas para populações carentes do meio urbano.

Scott (1999) apontou com propriedade para a mudança ocorrida em termos de formulações de políticas de saúde destinadas à população carente nos últimos anos. Segundo ele, a transição política no direcionamento de programas voltados para as populações pobres pode ser sentida pelo 
enfoque diferenciado para "segmentos sociais" ou "grupos sociais". Esta distinção sutil na forma de nomear tende a passar desapercebida, inclusive para os formuladores de políticas, mas auxilia o entendimento da mudança ocorrida ${ }^{12}$ e a pensar como o reconhecimento da diversidade pelos profissionais de saúde impõe novas possibilidades de diálogo com a população. As políticas de saúde com enfoque nos segmentos sociais (mulheres e adolescentes são prioritários) resultam em ações de saúde cujo alvo é o indivíduo que tende a ser considerado independente do seu contexto social. Já as políticas voltadas aos grupos sociais exigem estratégias que associem as demandas dos segmentos com a identidade da comunidade. $\mathrm{O}$ surgimento do Programa de Agentes Comunitários de Saúde/PACS e do Programa de Saúde na Família/PSF são exemplos significativos da mudança de direcionamento das políticas e ações já que, como aponta Scott (1999, p. 13), "introduz uma concepção de diversidade que se afirma na realidade contextualizada de comunidades e na necessidade de compreender a especificidade de suas demandas".

Nesta nova configuração das ações em saúde, a referência à diversidade em termos de opção religiosa se faz premente, isto porque, no caso do pentecostalismo, ela traz profundas implicações não apenas em termos de valores e atitudes de regulação do corpo, da sexualidade e saúde do sujeito que se converte, mas também, para a dinâmica familiar em que este se insere. Considerando a aposta de Duarte (2000) sobre a imbricação do saber e da prática médica com a lógica "selvagem" e "concreta" do povo, reconheço nesta nova direção que os programas assumem a possibilidade de uma mediação mais profunda entre esses dois mundos simbólicos. Tomando esta possibilidade de diálogo, constato a importância dos Agentes de Saúde inscritos nesses programas. Tendo suas identidades construídas $e$ referendadas neste universo da pobreza, podem, com sua participação nos programas de saúde, atuar, senão enquanto mediadores, como interlocutores desse diálogo.

Scott (1996) já apontou para a dificuldade que enfrenta o cientista social quando colocado na posição de mediador do diálogo entre os profissionais de saúde e a população. Não pretendo tratar aqui da polêmica acerca desse papel do cientista social. Neste trabalho, ao tratar da religiosidade e dos padrões de comportamento reprodutivo nas famílias de um grupo popular, busquei revelar a especificidade da cultura dos urbanos pobres do Ibura sem reproduzir a noção, ainda hoje arraigada no senso comum, de uma "cultura da pobreza" (Lewis, 1961). Ao utilizar um arsenal metodológico que auxiliou pensar a lógica da população como permeada de valores modernos $e$ tradicionais a um só tempo, procurei desnaturalizar o dado social. Em outras palavras, discutir a forma como os padrões de sociabilidade e reprodução social dos indivíduos em suas famílias são construídos. Isto sim, acredito, pode trazer elementos para os profissionais de saúde em
${ }^{12}$ Scott (1999) toma segmento social como uma categoria mais abstrata, onde algumas características são utilizadas para extrair as pessoas do contexto em que vivem; a identificação se dá por sexo, idade, renda, cor, etc. Já os grupos sociais reúnem referências mais concretas e complexas. Os grupos sociais congregam pessoas com características diversas que interagem com regularidade na vida cotidiana, por exemplo, grupos familiares, de parentesco, de vizinhança.

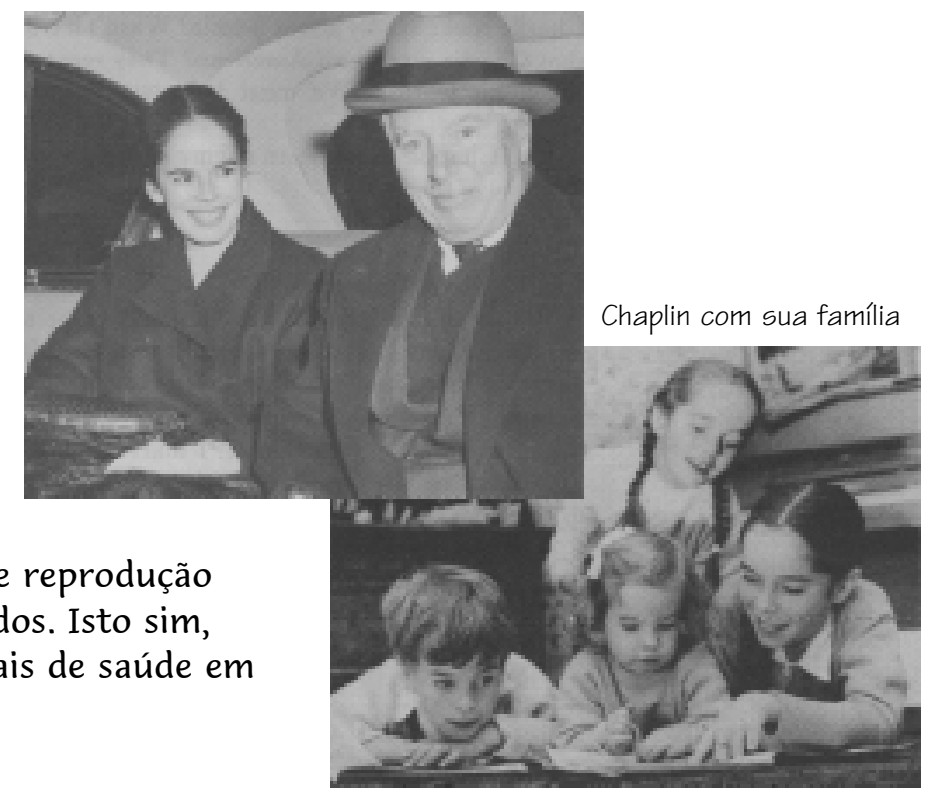


termos do reconhecimento da diversidade que permeia o universo das famílias pobres e, com isso, contribuir para o trabalho desses profissionais em formular e implementar ações mais sensíveis à diversidade destes grupos sociais; o que poderá levar, enfim, ao diálogo entre estes e as populações.

\section{Referências bibliográficas}

AUBRÉE, M. Voyages entre corps et esprits: étude comparative entre deux courants religieuses dans le Nordest brésilien. Paris, 1985. Tese (Doutorado) 3 éme Cicle, Universidade de Paris VII Jussieu.

BOURDIEU, P. A economia das trocas simbólicas. São Paulo: Perspectiva, 1982.

COUTO, M. Gestão comunitária e saúde em quatro comunidades do Ibura. In: SCOTT, R. Saúde e pobreza no Recife. Recife: Editora da UFPE, 1996. p.77-89.

COUTO, M. Comportamento reprodutivo, gênero, família e afiliação religiosa entre classes populares no Ibura. Relatório Final de Pesquisa CNPq/FACEPE. São Paulo, 2000. (mimeogr)

DA MATTA, R. O que faz o brasil, Brasil? Rio de Janeiro: Rocco, 1989.

DUARTE, L. Da vida nervosa nas classes trabalhadoras urbanas. Rio de Janeiro: Jorge Zahar, 1986.

DUARTE, L. A medicina e o médico na boca do povo. Rev. Anthropol. v.9, p.7-14, 2000.

DUMONT, L. O individualismo: uma perspectiva antropológica da ideologia moderna. Rio de janeiro: Rocco, 1993.

FERNANDES, R. et al. Novo nascimento: os evangélicos em casa, na igreja e na política. Rio de Janeiro: Mauad, 1998.

FRESTON, P. Breve história do pentecostalismo brasileiro. In: ANTONIAZZI, A. et al. Nem anjos nem demônios: interpretações sociológicas do pentecostalismo. Petrópolis: Vozes, 1994. p.67-162.

FREYRE, G. Casa grande e senzala. 32 ed. Rio de Janeiro: Record, 1997.

LEWIS, O. Antropología de la pobreza. México: Fondo de Cultura Económica, 1961.

MACHADO, M. Carismáticos e pentecostais: adesão religiosa na esfera familiar. São Paulo: Autores Associados/ANPOCS, 1996.

MACHADO, M. Sexualidade e contracepção em grupos religiosos brasileiros. In: SILVA, D. (Org.) Saúde, sexualidade e reprodução: compartilhando responsabilidades. Rio de Janeiro: Editora da UERJ, 1997. p.67-82.

MARIZ, C. Libertação e ética: análise do discurso de pentecostais que se recuperaram do alcoolismo. In: ANTONIAZZI, A. et al. Nem anjos nem demônios: interpretações sociológicas do pentecostalismo. Petrópolis: Vozes, 1994. p.204-224.

MARIZ, C., MACHADO, M. Changements récents dans le champ religieux bresilien. Soc. Compass. v.45, n.3, p.359-78, 1998.

MINAYO, M. Representação da cura no catolicismo popular. In: ALVES, P. C., MINAYO, M.C.S. (Orgs.) Saúde e doença: um olhar antropológico. Rio de Janeiro: Editora Fiocruz, 1998. p.57-72.

PAIM, H. Marcas no corpo: gravidez e maternidade em grupos populares. In: DUARTE, L., LEAL, O. (Orgs) Doença, sofrimento, perturbação: perspectivas etnográficas. Antropologia e Saúde. Rio de Janeiro: Fiocruz, 1998. p.98-115.

RABELLO, M. Religião, ritual e cura. In: ALVES, P. C., MINAYO, M. C. S. (Orgs.) Saúde e doença: um olhar antropológico. Rio de Janeiro: Editora Fiocruz, 1998. p.47-56.

SARTI, C. A família como espelho: um estudo sobre a moral dos pobres. Campinas: Autores Associados, 1996.

SCOTT, R. Saúde e pobreza no Recife. Recife: Editora da UFPE, 1996.

SCOTT, $R$. Transição política e a agenda de programas de saúde reprodutiva em regiões de periferias nacionais: o caso do NE brasileiro. Recife, 1999. (mimeogr.) 


\section{MÁRCIA COUTO}

VILLA, A. O significado da reprodução na construção da identidade masculina em setores populares urbanos. In: COSTA, A. (Org.) Direitos tardios: saúde, sexualidade e reprodução na América Latina. São Paulo: FCC/Ed. 34, 1997. p.59-72.

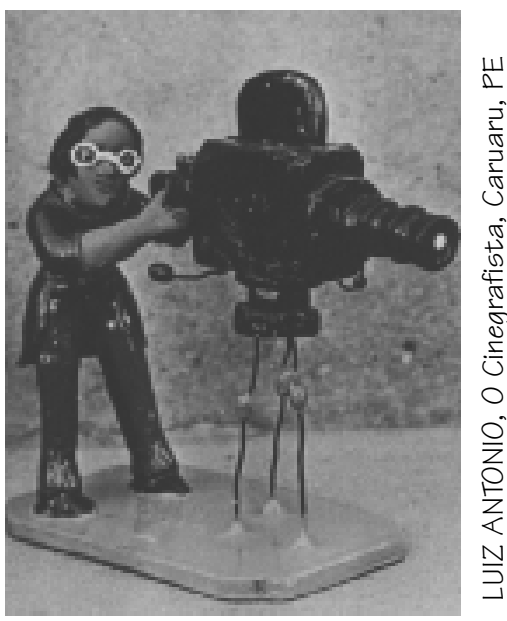

COUTO, M. T. Religiosidad, Reproducción y Salud en familias urbanas pobres. Interface Comunic, Saúde, Educ, v.5, n.8, p.27-44, 2001.

En este trabajo se analiza la conversión religiosa personal en el contexto de las relaciones familiares en un área de la periferia de la ciudad de Recife, Pernambuco - Brasil. Presenta resultados de una investigación de carácter cualitativo sobre los significados de la conversión para los integrantes de la familia y las resultantes transformaciones en el comportamiento reproductivo. Por fin, con base en el material empírico, se apuntan ciertas cuestiones sobre los servicios de salud existentes en el barrio y el uso que hace de ellos la población.

PALABRAS-CLAVE: religión; poblacion urbana; relaciones familiares; reproduccion; servicios de salud.

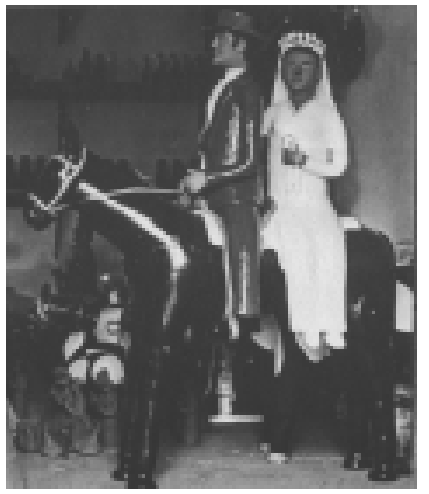

MANUEL EUDÓCIO, Casamento na roça, Caruaru, PE 